\title{
Short communication: Toxicokinetics of ochratoxin A in dairy ewes and carryover to milk following a single or long-term ingestion of contaminated feed
}

\author{
H. Boudra, ${ }^{*}$ S. Saivin, $†$ C. Buffiere, $\ddagger$ and D. P. Morgavi*1 \\ *INRA, UMR1213 Herbivores, F-63122 Saint-Genès-Champanelle and Clermont Université, VetAgro Sup, UMR Herbivores, BP 10448, F-63000, \\ Clermont-Ferrand, France \\ †Laboratoire de Pharmacocinétique et Toxicologie Clinique, Institut Fédératif de Biologie, 133 Avenue de Grande Bretagne, \\ 31059 Toulouse Cedex 9, France \\ ‡Clermont Université, Université d'Auvergne, Unité de Nutrition Humaine, BP 10448, F-63000, Clermont-Ferrand, France
}

\begin{abstract}
Ruminal microbes have the capacity to inactivate ochratoxins, rendering ruminants less sensitive to this fungal contaminant found in cereal feeds. However, ochratoxin A has been reported in milk surveys. The objective of this study was to assess the toxicokinetics, excretion, and transmission into milk of ochratoxin A using doses similar to those of naturally occurring field contaminations. Six Lacaune dairy ewes in late lactation were separated into 2 groups that received a single dose of contaminated wheat containing 5 or 30 $\mu \mathrm{g}$ of ochratoxin $\mathrm{A} / \mathrm{kg}$ of body weight. After administration, toxicokinetics and excretion were monitored for $48 \mathrm{~h}$. Subsequently, ewes were administered the corresponding toxin dose daily for $24 \mathrm{~d}$ followed by a second toxicokinetics and excretion monitoring period for this long-term exposure. The doses used did not affect production or health of ewes. After a single dose, ochratoxin A and its main metabolite, ochratoxin $\alpha$, were found in blood $1 \mathrm{~h}$ postexposure. The maximum blood concentrations of ochratoxin A and $\alpha$, respectively, were dose dependent and were observed, on average, 6 and $8 \mathrm{~h}$ after exposure. Long-term exposure increased the maximum concentration of ochratoxin A detected in blood, whereas ochratoxin $\alpha$ was not affected. In contrast, the time to reach the maximum concentration was reduced to $3 \mathrm{~h}$ for both molecules. Ochratoxins, essentially ochratoxin $\alpha$, were mainly excreted in feces. Ochratoxin A and $\alpha$ were detected in milk at concentrations that were dose dependent but with a low carryover rate $(<0.02 \%)$. Chronic administration did not increase the concentration of toxin in milk. Even though ochratoxin A can escape ruminal degradation and traces were found in milk of experimentally ex-
\end{abstract}

Received February 18, 2013.

Accepted July 4, 2013.

${ }^{1}$ Corresponding author: diego.morgavi@clermont.inra.fr posed ewes, the low carryover of ochratoxin A in milk minimizes the risk to consumers.

Key words: mycotoxin, dairy ewe, toxicokinetics, milk transfer

\section{Short Communication}

Ochratoxins (OT), a group of highly toxic metabolites produced by some species of Aspergillus and Penicillium, are commonly found in feeds (Binder et al., 2007; Duarte et al., 2011). Ochratoxin A (OTA), the most important toxin of this family, is nephrotoxic, hepatotoxic, teratogenic, and carcinogenic in animals. Ruminants are considered to be more resistant to the toxic effects of OTA than monogastric animals because this toxin is hydrolyzed by rumen microorganisms into the less toxic metabolite ochratoxin $\alpha$ (OT $\mathbf{\alpha}$; Kiessling et al., 1984; Özpinar et al., 1999). The conversion by rumen microorganisms is rapid, with an average halflife of $3 \mathrm{~h}$ in the rumen (Mobashar et al., 2010). It has been calculated that ruminants can safely inactivate OTA concentrations of up to $12,000 \mu \mathrm{g} / \mathrm{kg}$ of feed (Hult et al., 1976), a concentration that is several fold higher than that normally reported in naturally contaminated feeds (Mobashar et al., 2010; Duarte et al., 2011). However, experimental exposure of animals to a fraction of the theoretical inactivating capacity of ruminal microbes revealed that the inactivation or transformation is incomplete because OTA was found in blood and urine (Hohler et al., 1999; Blank et al., 2003). In addition, OTA has been detected in milk surveys in some countries (Breitholtz-Emanuelsson et al., 1993; Skaug, 1999; Boudra et al., 2007). Although the sporadic frequency and low OTA concentration in milk-positive samples precludes a public health problem, there is insufficient information on the rate of passage of OTA into ruminant milk and on the extent to which dietary OTA at low doses is absorbed, thus escaping microbial rumen degradation, in exposed ruminants. 
In this study, we examined the effect of a single dose or chronic OTA ingestion on the toxicokinetics, excretion, and transmission into milk of OTA and OTa in dairy ewes. The doses used were comparable to levels of OTA that animals fed naturally contaminated feeds might receive. Contamination with OTA is more prevalent in cereals such as corn, wheat, and barley but it can also be found in other feed components and forages (Binder et al., 2007; Mobashar et al., 2010). Although it is usually found at concentrations of a few micrograms per kilogram of feed, high levels of $>1,000 \mu \mathrm{g} /$ $\mathrm{kg}$ have been reported in several surveys (EFSA, 2004; Mobashar et al., 2010; Duarte et al., 2011).

Contaminated feed was prepared under controlled laboratory conditions using an Aspergillus ochraceus strain (a high producer of OTA) grown on wheat incubated at $28^{\circ} \mathrm{C}$ for $4 \mathrm{wk}$. At the end of the incubation period, the cultures were dried at $45^{\circ} \mathrm{C}$ for $48 \mathrm{~h}$ in a forced-air oven, pooled, and ground to pass a $1-\mathrm{mm}$ screen. Ochratoxins in the homogenized sample were analyzed in quadruplicate as described previously (Boudra and Morgavi, 2006). The concentration of OTA was $237.3 \pm 16.0 \mu \mathrm{g} / \mathrm{g}$ (mean $\pm \mathrm{SD}$ ) and was used to calculate the dose given to sheep; ochratoxin B (OTB) was also present at a low concentration of 13.7 $\pm 0.5 \mu \mathrm{g} / \mathrm{g}$.

Animals were cared for in accordance with the guidelines for animal research of the French Ministry of Agriculture and applicable European guidelines and regulations for experimentation with animals (http://www2. vet-lyon.fr/ens/expa/acc_regl.html). The experiment was approved by the Auvergne regional ethic committee for animal experimentation (approval number $\mathrm{CE}$ 4-05). Ochratoxin A is a possible human carcinogen. The contaminated wheat was manipulated in a dedicated safety hood for dose preparation, and personnel wore coats, disposable gloves, protective masks, and goggles when handling the wheat. For analysis, appropriate laboratory safety precautions for handling mycotoxins were followed. Six healthy Lacaune dairy ewes in late lactation with a mean $\mathrm{BW}$ of $76.3 \pm 8.6$ $\mathrm{kg}$ were used. Ewes were $2 \mathrm{yr}$ old and in their second lactation. Ewes were fed prairie hay $(\mathrm{CP}=13.5, \mathrm{NDF}$ $=61.4, \mathrm{ADF}=32.8$, ash $=9.0, \%$ on a $\mathrm{DM}$ basis $) \mathrm{ad}$ libitum and a concentrate mixture of $0.5 \mathrm{~kg}$ of pelleted wheat $(\mathrm{CP}=12.2, \mathrm{NDF}=24.2, \mathrm{ADF}=3.1$, ash $=$ $1.8, \%$ on a DM basis) and $0.3 \mathrm{~kg}$ of soybean meal $(\mathrm{CP}=51.5, \mathrm{NDF}=23, \mathrm{ADF}=5.8$, ash $=4.5, \%$ on a DM basis) per day. The concentrate was supplied in 2 equal parts at the time of milking at 0800 and 1630 h. All feed components tested negative for the presence of mycotoxins commonly produced by $A$. ochraceus: OTA, OTB, citrinin, and penicillic acid. Fresh water and a mineral salt block were available all the time to animals. Ewes were randomly divided into 2 groups based on BW and milk production. One group received the low dose of $5 \mu \mathrm{g}$ of OTA $/ \mathrm{kg}$ of BW per day and the other received the high dose of $30 \mu \mathrm{g}$ of OTA $/ \mathrm{kg}$ of BW per day. The OTA-contaminated wheat was dispensed in gelatin capsules that were administered orally before the morning feeding using a bolus applicator. This procedure ensured the complete ingestion of the desired toxin amount.

Ewes were acclimatized to the barn environment and diet for $4 \mathrm{wk}$; $2 \mathrm{wk}$ before toxin administration, animals were gradually adapted to the administration of boluses (filled with noncontaminated ground wheat) and to metabolism cages. The experimental design consisted of a 7-d period without toxin, followed by a single toxin administration and a 2-d toxicokinetic measurement period. Four days after the single administration, toxin was administered daily for $24 \mathrm{~d}$ and a second period of toxicokinetic measurements occurred at the end of this longer term exposure. Body weights, milk yield, intake, and digestion were monitored throughout the experiment.

Blood samples were collected from the jugular vein into heparinized tubes and centrifuged $(3,000 \times g, 15$ min, $4^{\circ} \mathrm{C}$ ), and the plasma was transferred into clean tubes and stored at $-20^{\circ} \mathrm{C}$ until analysis. For kinetic measurements, 11 samples $(0,1,2,3,6,9,12,24,30$, 36 , and $48 \mathrm{~h})$ and 16 samples $(0,1,2,3,6,9,12,24$, $30,36,48,72,96,120,150$, and $168 \mathrm{~h}$ ) were taken following toxin administration in the first and second toxicokinetic periods, respectively. Samples were also taken before exposure on $\mathrm{d}-7$ and -1 and on $\mathrm{d} 1,6$, $9,15,22$, and 28 of the exposure period. Milk samples of $100 \mathrm{~mL}$ were collected daily throughout the experiment, preserved by adding $1.5 \mu \mathrm{g} / \mathrm{mL}$ of sodium azide, and stored at $-20^{\circ} \mathrm{C}$ until analysis.

Feces and urine were collected over a period of $4 \mathrm{~d}$ at 4 different times during the experiment. These periods were before toxin administration ( $\mathrm{d}-3$ to 0 ), during the 2 plasma kinetic measurements at the start (d 1 to 4) and end (d 29 to 31) of toxin administration, and at mid-exposure time (d 15 to 18). Feces collected daily were homogenized and stored at $-20^{\circ} \mathrm{C}$ until analysis for mycotoxins. Total-tract digestion was measured by a total fecal collection technique. Feces gathered over the 4-d collection period were pooled for each ewe, dried at $80^{\circ} \mathrm{C}$, ground to pass a $1-\mathrm{mm}$ screen, and retained for chemical analyses as done for feeds. For urine, samples were preserved at low $\mathrm{pH}(<3)$ during collection by using $\mathrm{HCl}$. The daily total volume was recorded and aliquots were stored at $-20{ }^{\circ} \mathrm{C}$ until analysis. Ochratoxins in different matrices were extracted and analyzed as previously described (Boudra and Morgavi, 2006). Briefly, acidified $(\mathrm{pH}<2)$ samples were extracted with an equal 
volume of chloroform. The toxin in the organic layer was back-extracted with $8 \mathrm{~mL}$ of PBS, $\mathrm{pH} 7.6$, and the top aqueous layer was then loaded into an immunoaffinity column (Ochraprep, R-Biopharm, Lyon, France). Ochratoxins were eluted with methanol, the purified extracts were evaporated to dryness at $45^{\circ} \mathrm{C}$ under a stream of nitrogen gas, and the dried residues were dissolved in $200 \mu \mathrm{L}$ of mobile phase. A $50-\mu \mathrm{L}$ volume of these extract solutions was injected into an HPLC system (Thermo Finnigan, Paris, France) equipped with a fluorescence detector (FL-3000, Thermo Finnigan). Separation was performed at room temperature on a Nucleodur $\mathrm{C}_{18}$ Gravity column $(125 \times 4.6 \mathrm{~mm}, 5 \mu \mathrm{m}$, Macherey Nagel, Lyon, France), using an isocratic mobile phase of acetonitrile-10\% acetic acid (54:46 ratio). Excitation and emission in the detector were set at 334 $\mathrm{nm}$ and $440 \mathrm{~nm}$, respectively. Recovery, linearity, precision, accuracy, sensitivity, and stability were tested as previously described.

Noncompartmental analysis was used to estimate the toxicokinetic parameters of OTA and OTa by using Kinetica version 4.0 (Thermo/Innaphase, Philadelphia, PA): Cmax and Tmax were observed values defined as the maximum concentration and the time to reach it; $\mathbf{A} \mathbf{U} \mathbf{C}_{0 \text {-last }}$ was the area under the time concentration curve, calculated by the trapezoidal method between the first and the last measurable concentration; $\mathbf{A U C}_{0-\infty}$ was $\mathrm{AUC}_{0 \text {-last }}$ extrapolated to infinity by the ratio of the last measurable concentration to the terminal slope $\mathbf{k}_{\mathrm{e}}$; and $\mathbf{T}_{1 / 2}$ was the terminal half-life determined as the ratio of natural logarithm of 2 to the terminal slope $\mathbf{k}_{\mathrm{e}}$. The ratio of Cmax and AUC to the administered dose was calculated to investigate the toxicokinetic linearity. Accumulation was studied by the ratio of $\mathrm{AUC}_{0-24}$ (AUC from 0 to $24 \mathrm{~h}$ ) on $\mathrm{d}$ 28 to $\mathrm{AUC}_{0-\infty}$ of the single dose on $\mathrm{d} 1$. These toxicokinetic parameters were statistically analyzed using the MIXED procedure of SAS (version 9, SAS Institute Inc., Cary, NC), with the following mixed linear model:

$$
\mathrm{y}_{\mathrm{ijk}}=\mu+\mathrm{D}_{\mathrm{i}}+\mathrm{E}_{\mathrm{j}}+(\mathrm{D} \times \mathrm{E})_{\mathrm{ij}}+\mathrm{A}_{(\mathrm{i}) \mathrm{k}}+\varepsilon_{\mathrm{ijk}},
$$

where $y$ is the dependent variable, $\mu$ is the overall mean, $\mathrm{D}$ is the fixed effect of the OTA dose, $\mathrm{E}$ is the fixed effect of the single or long-term exposure, $\mathrm{D} \times \mathrm{E}$ is the dose $\times$ exposure interaction, $\mathrm{A}$ is the random effect of animal tested within dose, and $\varepsilon$ is the random residual. Digestibility was analyzed using the same model and excretion parameters were analyzed using nonparametric tests (SAS Institute Inc.). The Wilcoxon test was used to compare the effect of dose and the signed rank test was used to compare the effects of single and longterm exposure. Dry matter intake, milk production, and milk quality parameters were analyzed using the generalized linear model for repeated measures (SAS Institute Inc.) and the best fitting covariance structure. For DMI, 6 data points were used, representing the daily DMI average of the week before and the 5 wk of exposure. For milk production, the daily average of the 4 wk of acclimatization and the 5 wk of exposure were used, and for milk parameters, wk 2, 3, and 5 of the exposure were used. The model was

$$
\mathrm{y}_{\mathrm{ijk}}=\mu+\mathrm{D}_{\mathrm{i}}+\mathrm{A}_{(\mathrm{i}) \mathrm{j}}+\mathrm{T}_{\mathrm{k}}+(\mathrm{DT})_{\mathrm{ik}}+\varepsilon_{\mathrm{ijk}},
$$

where $y$ is the dependent variable, $\mu$ is the overall mean, $\mathrm{D}$ is the fixed effect of the OTA dose, A is animal effect within dose treatment, $\mathrm{T}$ is day of sampling effect, DT is the interaction of OTA dose $\times$ day of sampling, and $\varepsilon$ is the error. Significance was declared at the $5 \%$ probability level and trends were discussed at the $10 \%$ probability level.

No overt clinical or production problems were observed during the exposure period. The absence of toxic effects was expected given the doses used, in accordance with previous reports using similar (Blank et al., 2003) or higher doses (Hohler et al., 1999) in sheep. Feed intake did not vary throughout the experimental period, irrespective of the dose $(P>0.05)$. Mean daily DMI of hay and concentrate was 1.48 and $0.70 \mathrm{~kg}$, respectively. Ewes lost weight during the experiment, from the initial BW of $76.3 \pm 8.6 \mathrm{~kg}$ (mean $\pm \mathrm{SD}$ ) to $71.0 \pm 8.0$ $\mathrm{kg}(P<0.05)$. This loss was recorded in wk 2 of the long-term exposure period (just after the measures in metabolism cages were taken) but remained constant thereafter until the end of the trial. Although an effect of the toxin cannot be totally excluded, the most plausible explanation is that ewes had difficulty adapting to the metabolism cages. In particular, 1 ewe on the high dose group that did not lie down while in the cage had reduced intake and lost $14 \mathrm{~kg}$ between the start of the experiment and wk 2. Because of this, digestibility was considered only in the low dose group. No differences were observed in DM, NDF, and ADF digestibility of the ration before and after long-term exposure to the low OTA dose $(P>0.05)$.

Milk production at the start and end of the experimental period averaged $( \pm \mathrm{SD}) 1.66 \pm 0.29$ and 1.15 $\pm 0.42 \mathrm{~kg} / \mathrm{d}$, respectively $(P<0.01)$. The reduction in milk production was considered normal for latelactation ewes, and no difference between groups was observed $(P>0.05)$. Milk constituents that were monitored at the start, middle, and end of the long-term exposure showed no changes in lipids, protein, lactose, or SCC $(P>0.05)$. In contrast, urea increased with time in both groups $(P<0.01$; data not shown $)$. 
Before initial exposure of ewes on d 0 of the experiment, there was no detectable OTA or ochratoxin B in plasma. Table 1 shows toxicokinetic parameters of OTA and OT $\alpha$ after a single dose or after a 4 -wk exposure period. The peak concentration (Cmax) and area under the curve $\left(\mathrm{AUC}_{0 \text {-last }}\right)$ of both molecules were particularly influenced by dose. As expected, values were higher with the high dose. The ratios of $\mathrm{Cmax}$ and $\mathrm{AUC}_{0 \text {-last }}$ to the administered dose tended to be or were numerically higher in the long-term exposure compared with the single dose. The Cmax of the high OTA dose in particular was 2.4 times higher than for the corresponding dose without previous exposure $(P<0.05)$. The increase due to dose, however, was not proportional. The reason for this nonlinearity is not known. Given the low doses used, it seems unlikely to be explained by saturation of protein binding sites or by decreased ruminal escape. The time to reach the peak (Tmax) was reduced by half for both molecules in the long-term exposure. Plasma profiles of OTA and OTa are shown in Figure 1. Plasma profiles of OT $\alpha$ had a double peak for the single dose exposure, which explains the higher Tmax compared with long-term exposure (Figure 1B).

Little information exists on disposition of OTA in sheep (Xiao et al., 1991; Blank and Wolffram, 2009) and only a single report in ruminant calves was found (Sreemannarayana et al., 1988). Ruminants exposed to a single OTA dose of $500 \mu \mathrm{g} / \mathrm{kg}$ of BW or higher (Sreemannarayana et al., 1988; Xiao et al., 1991) presented 2 peaks in blood, the second absorption phase resulting from enterohepatic cycling of the toxin. We observed instead a minor double peak for OT $\alpha$ but none for OTA. The difference might be due to sheep or cattle characteristics or to the nature of the toxin and the dose. We used a contaminated feed administered at a maximum dose of $30 \mu \mathrm{g}$ of OTA $/ \mathrm{kg}$ of BW, whereas in the experiments of Sreemannarayana et al. (1988) and Xiao et al. (1991), the toxin was obtained from a liquid culture concentrate and was administered at a dose that was more than 15 times higher. Blank and Wolffram (2009), who used contaminated feed in a single dose similar to the higher concentration used in our study, also found a monoexponential decline in blood OTA with similar toxicokinetic parameters.

We observed large differences among individuals in the excretion of OT in urine and feces that were particularly important for OTA (the 48-h cumulative excretion of OT is shown in Supplementary Table S1; http://dx.doi.org/10.3168/jds.2013-6707). In the low dose group, values of OTA in urine were mainly from a single ewe. For the high dose group and after the long-term exposure, 1 ewe had a high concentration of OTA in urine (individual data not shown). Average OTA elimination in urine and feces was low com-

Table 1. Toxicokinetic parameters of ochratoxin A and its metabolite ochratoxin $\alpha$ in dairy ewes after a single dose or long-term (4 wk) exposure to feed contaminated with ochatoxin $\mathrm{A}$ at a low $\left(5 \mu \mathrm{g} / \mathrm{kg}\right.$ of BW) or high $\left(30 \mu \mathrm{g} / \mathrm{kg}\right.$ of BW) dose ${ }^{1}$

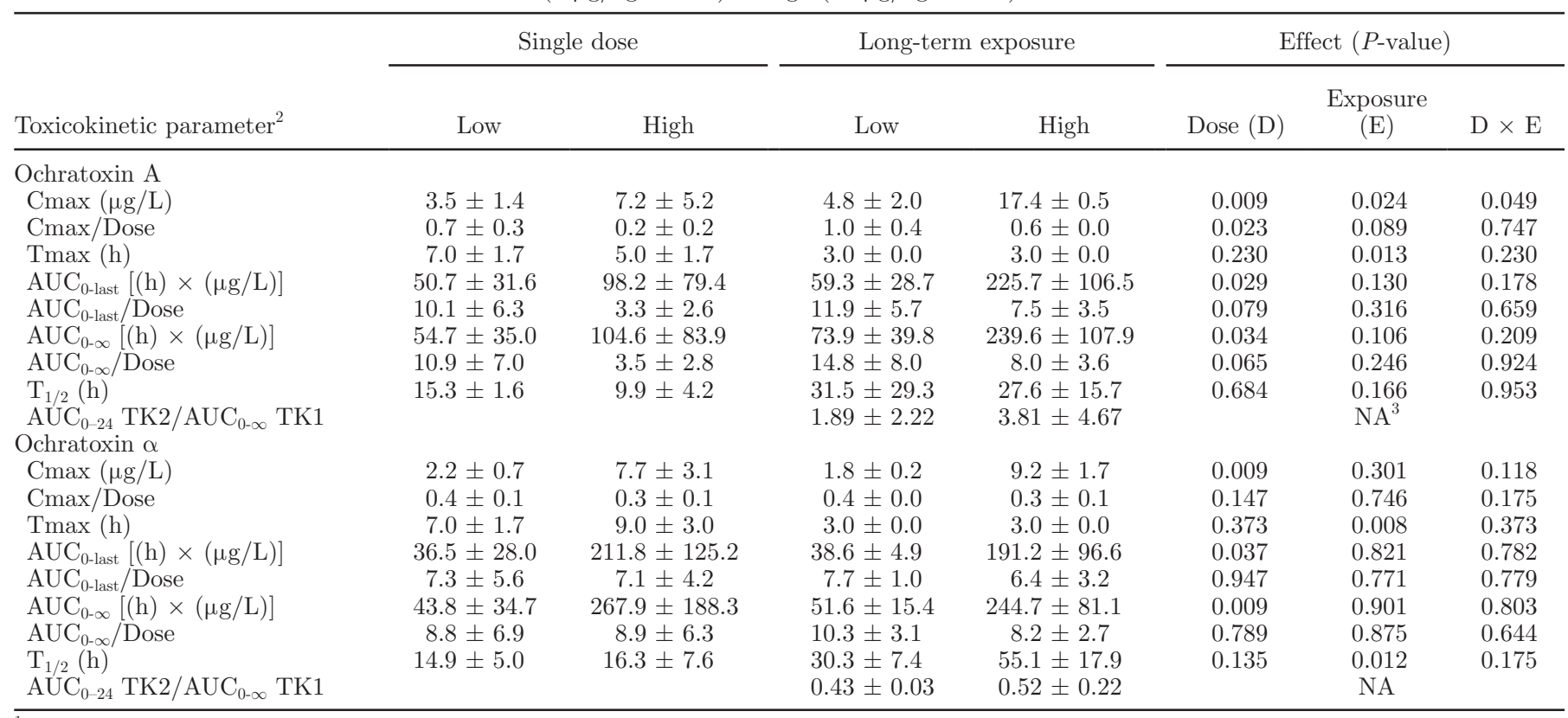

${ }^{1}$ Data are means $\pm \mathrm{SD} ; \mathrm{n}=3$ per dose.

${ }^{2} \mathrm{Cmax}=$ maximum concentration; Tmax $=$ time to reach $\mathrm{Cmax} ; \mathrm{AUC}_{0 \text {-last }}=$ area under the time-concentration curve; $\mathrm{AUC}_{0-\infty}=\mathrm{AUC}_{0 \text {-last }}$ extrapolated to infinity; $\mathrm{T}_{1 / 2}=$ terminal half-life; $\mathrm{AUC}_{0-24}=\mathrm{AUC}$ from 0 to $24 \mathrm{~h}$; TK1 = toxicokinetic single dose; TK2 $=$ toxicokinetic longterm exposure.

${ }^{3}$ Not applicable. 

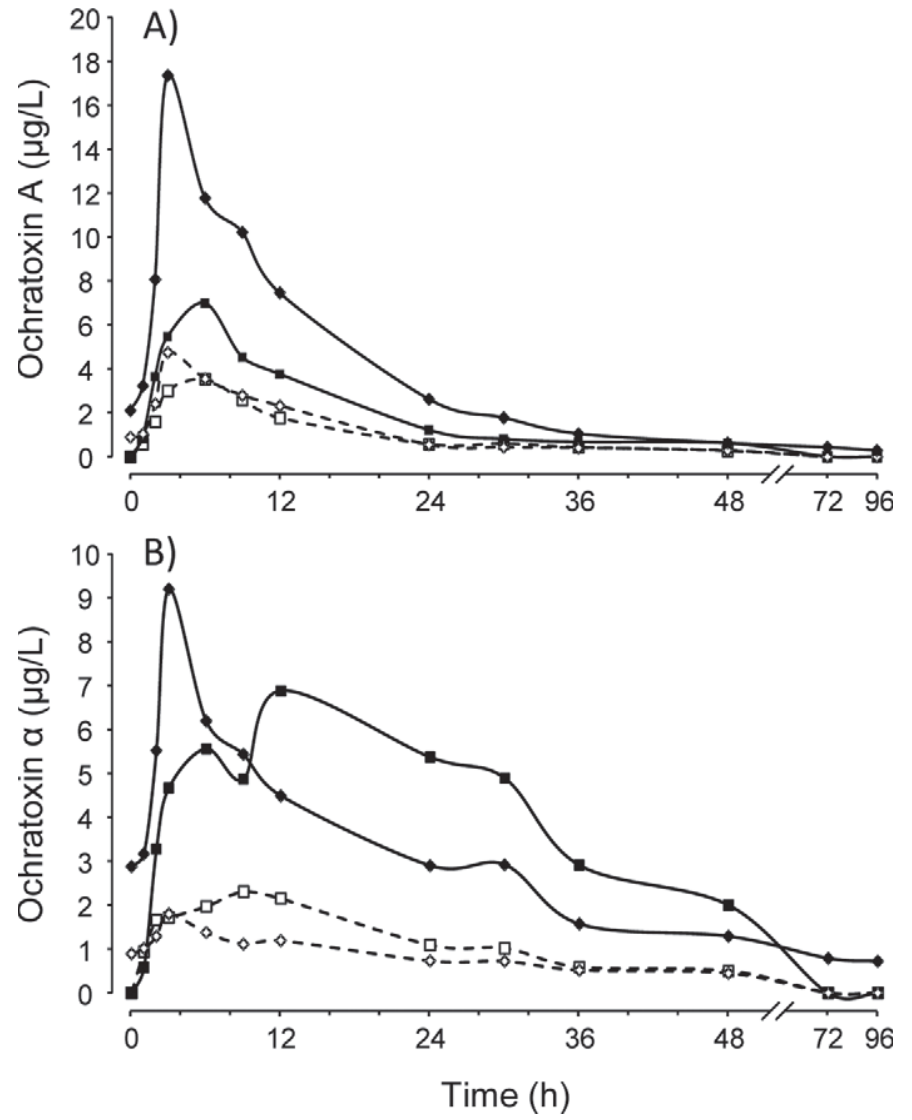

Figure 1. Toxicokinetics of ochratoxin A (A) and its main metabolite ochratoxin $\alpha$ (B) in plasma of ewes after a single dose $(\mathbf{\square}, \square)$ or after 4 wk of exposure $(\diamond, \diamond)$ to feed contaminated with ochratoxin A at 5 (low, open symbols) and 30 (high, solid symbols) $\mu \mathrm{g} / \mathrm{kg}$ of BW.

pared with that of OT $\alpha$. The dose used affected OTA elimination in feces but not in urine. In contrast, the elimination of OT $\alpha$ with the higher dose increased in urine $(P=0.004)$ and tended to increase in feces $(P$ $=0.065)$. An increased amount of OT $\alpha$ eliminated in feces was observed following long-term exposure $(P$ $=0.031)$ and can be partly explained because toxins were administered daily but elimination took about 4 d (data not shown). In addition, this increased OTa in feces coupled with numerically lower OTA elimination in urine following long-term exposure might suggest better detoxification by the microbiota.

Ochratoxin A and OT $\alpha$ were detected in milk at concentrations that were dose dependent but with a low carryover rate of less than $0.02 \%$ for OTA (Table 2). Concentrations in milk, although generally higher than reported in surveys from dairy cow milk in several countries (Breitholtz-Emanuelsson et al., 1993; Skaug, 1999; Boudra et al., 2007), confirm the low rate of transfer of this toxin into ruminant milk (Fink-Gremmels, 2008; Mobashar et al., 2010). Similar to results in plasma, the concentration of OTA in milk varied largely between ewes. In contrast, intra-individual concentrations remained relatively constant from wk 1 until the end of the 4-wk experimental period. The milk-to-plasma OTA ratio measured at regular intervals (d 6, 15, 22, and 28) during the steady-state, long-term exposure varied from 0.04 to 0.21 (data not shown). Following the last dose, OTA and OT $\alpha$ clearance in milk continued for a few days but with a steady reduction in the daily amount detected; up to $10 \%$ of the maximum OTA concentration was detected after $4 \mathrm{~d}$ postdosing (Figure 2). Inter-individual variation in OTA concentration in milk has also been reported in humans (Ringot et al., 2006). In humans, the milk to plasma ratio is reported to be 0.1 or lower (Breitholtz-Emanuelsson et al., 1993). In the current study, the presence of OTA in milk and urine was observed after animals received

Table 2. Ochratoxin A and its main metabolite ochratoxin $\alpha$ transfer in milk of ewes after a single dose or long-term (4 wk) exposure to feed contaminated with ochatoxin A at a low $(5 \mu \mathrm{g} / \mathrm{kg}$ of BW) or high $(30 \mu \mathrm{g} /$ $\mathrm{kg}$ of BW) dose $\mathrm{I}^{\mathrm{I}}$

\begin{tabular}{|c|c|c|c|c|c|c|c|}
\hline \multirow[b]{2}{*}{ Item } & \multicolumn{2}{|c|}{ Single dose } & \multicolumn{2}{|c|}{ Long-term exposure } & \multirow[b]{2}{*}{ SEM } & \multicolumn{2}{|c|}{$P$-value } \\
\hline & Low & High & Low & High & & Dose & Exposure \\
\hline Milk yield $^{1}(\mathrm{~L})$ & 1.59 & 1.52 & 1.10 & 1.32 & 0.296 & 0.79 & 0.031 \\
\hline \multicolumn{8}{|l|}{ Ochratoxin A } \\
\hline Output $^{2}$ (ng) & 42 & 323 & 44 & 209 & 137.2 & 0.004 & 0.63 \\
\hline Concentration $(\mathrm{ng} / \mathrm{L})$ & 27 & 175 & 40 & 158 & 41.7 & 0.004 & 1 \\
\hline Carryover $(\%)$ & 0.012 & 0.016 & 0.012 & 0.011 & 0.0079 & 0.54 & 0.44 \\
\hline \multicolumn{8}{|l|}{ Ochratoxin $\alpha$} \\
\hline Output (ng) & 51 & 930 & 483 & 1.551 & 288.2 & 0.026 & 0.031 \\
\hline Concentration $(\mathrm{ng} / \mathrm{L})$ & 32 & 532 & 420 & 1,213 & 92.7 & 0.009 & 0.031 \\
\hline Carryover $^{3}(\%)$ & 0.024 & 0.074 & 0.215 & 0.120 & 0.0463 & 1 & 0.031 \\
\hline
\end{tabular}

${ }^{1}$ Mean volume produced $24 \mathrm{~h}$ postdosing.

${ }^{2}$ Mean toxin excreted $24 \mathrm{~h}$ postdosing.

${ }^{3}$ Expressed in terms of ochratoxin A equivalents: ochratoxin $\alpha(\mu \mathrm{g}) \times 1.573$ factor (MW ochratoxin A/MW ochratoxin $\alpha$ ), where $\mathrm{MW}=$ molecular weight. 

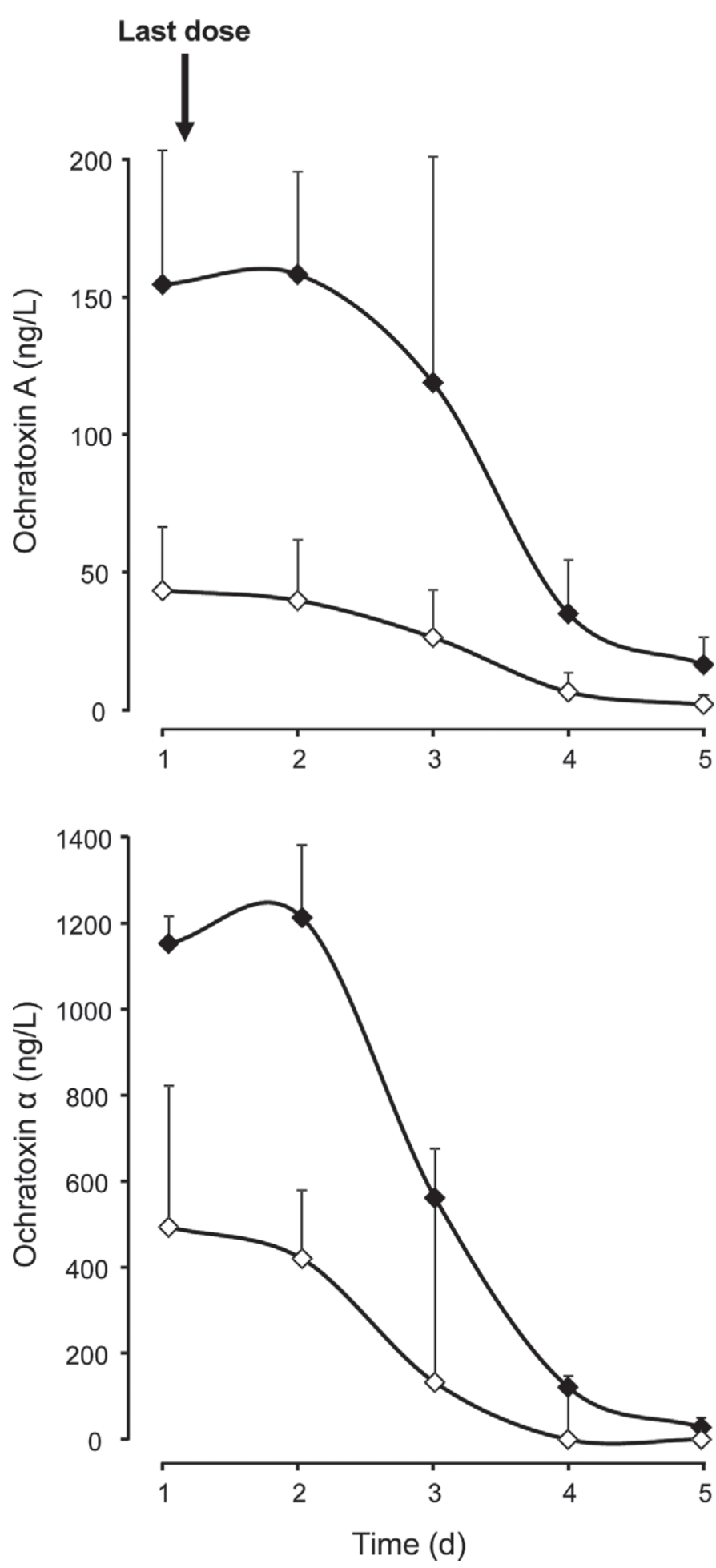

Figure 2. Daily excretion of ochratoxin A and its main metabolite ochratoxin $\alpha$ in milk of ewes measured the day before and for $4 \mathrm{~d}$ after the last dose of feed contaminated with ochratoxin A at 5 (low, open symbols) and 30 (high, solid symbols) $\mu \mathrm{g} / \mathrm{kg} \mathrm{BW}$ following 4 wk of exposure. doses several fold lower than the degrading capacity of the rumen. This can be explained because a proportion of OTA escapes microbial ruminal degradation due to passage of contents from the rumen (Mobashar et al., 2010). The absorption of OTA through the rumen epithelium, which remains to be quantified, may also reduce microbial degradation increasing passage into the bloodstream.

In conclusion, OTA that is present in naturally contaminated feeds escapes ruminal degradation and can be found in blood (confirming previous studies: Hohler et al., 1999; Blank et al., 2003) and, albeit in lower quantities, in ewe milk. Long-term exposure to OTA showed no significant effect on OTA excretion. Milk can contain traces of OTA even when animals are chronically exposed to low concentrations of this toxin in feeds. In contrast, OT $\alpha$ excretion increased following long-term exposure, suggesting improved microbial detoxification.

\section{ACKNOWLEDGMENTS}

We gratefully acknowledge A. Combeau, C. Mathevon, and D. Roux from the UE1354 Ruminant Experimental Unit (Saint-Genès-Champanelle, France) for the care of animals; D. Alvarez, D. Graviou, and R. Bergeault for their technical assistance; and J.-P. Jouany for helpful discussions (all at INRA, UMR1213 Herbivores, SaintGenès-Champanelle, and Clermont Université, VetAgro Sup, UMR Herbivores, Clermont-Ferrand, France).

\section{REFERENCES}

Binder, E. M., L. M. Tan, L. J. Chin, J. Handl, and J. Richard. 2007. Worldwide occurrence of mycotoxins in commodities, feeds and feed ingredients. Anim. Feed Sci. Technol. 137:265-282.

Blank, R., J. P. Rolfs, K. H. Sudekum, A. A. Frohlich, R. R. Marquardt, and S. Wolffram. 2003. Effects of chronic ingestion of ochratoxin $\mathrm{A}$ on blood levels and excretion of the mycotoxin in sheep. J. Agric. Food Chem. 51:6899-6905.

Blank, R., and S. Wolffram. 2009. Effects of live yeast cell supplementation to high concentrate diets on the toxicokinetics of ochratoxin A in sheep. Food Addit. Contam. A Chem. Anal. Control Expo. Risk Assess. 26:119-126.

Boudra, H., J. Barnouin, S. Dragacci, and D. P. Morgavi. 2007. Aflatoxin $\mathrm{M}_{1}$ and ochratoxin $\mathrm{A}$ in raw bulk milk from French dairy herds. J. Dairy Sci. 90:3197-3201.

Boudra, H., and D. P. Morgavi. 2006. Development and validation of a HPLC method for the quantitation of ochratoxins in plasma and raw milk. J. Chromatogr. B Analyt. Technol. Biomed. Life Sci. 843:295-301.

Breitholtz-Emanuelsson, A., M. Olsen, A. Oskarsson, I. Palminger, and K. Hult. 1993. Ochratoxin A in cow's milk and in human milk with corresponding human blood samples. J. AOAC Int. $76: 842-846$.

Duarte, S. C., C. M. Lino, and A. Pena. 2011. Ochratoxin A in feed of food-producing animals: An undesirable mycotoxin with health and performance effects. Vet. Microbiol. 154:1-13.

EFSA. 2004. Opinion of the scientific panel on contaminants in food chain on a request from the commission related to ochratoxin A (OTA) as undesirable substance in animal feed. EFSA J. 101:1-36. 
Fink-Gremmels, J. 2008. Mycotoxins in cattle feeds and carry-over to dairy milk: A review. Food Addit Contam. A Chem. Anal. Control Expo. Risk Assess. 25:172-180.

Hohler, D., K. H. Sudekum, S. Wolffram, A. A. Frohlich, and R. R. Marquardt. 1999. Metabolism and excretion of ochratoxin A fed to sheep. J. Anim. Sci. 77:1217-1223.

Hult, K., A. Teiling, and S. Gatenbeck. 1976. Degradation of ochratoxin A by a ruminant. Appl. Environ. Microbiol. 32:443-444.

Kiessling, K. H., H. Pettersson, K. Sandholm, and M. Olsen. 1984. Metabolism of aflatoxin, ochratoxin, zearalenone, and three trichothecenes by intact rumen fluid, rumen protozoa, and rumen bacteria. Appl. Environ. Microbiol. 47:1070-1073.

Mobashar, M., J. Hummel, R. Blank, and K. H. Sudekum. 2010. Ochratoxin $\mathrm{A}$ in ruminants - $\mathrm{A}$ review on its degradation by gut microbes and effects on animals. Toxins (Basel) 2:809-839.
Özpinar, H., G. Augonyte, and W. Drochner. 1999. Inactivation of ochratoxin in ruminal fluid with variation of $\mathrm{pH}$ value and fermentation parameters in an in vitro system. Environ. Toxicol. Pharmacol. 7:1-9.

Ringot, D., A. Chango, Y.-J. Schneider, and Y. Larondelle. 2006. Toxicokinetics and toxicodynamics of ochratoxin A, an update. Chem. Biol. Interact. 159:18-46.

Skaug, M. A. 1999. Analysis of Norwegian milk and infant formulas for ochratoxin A. Food Addit. Contam. 16:75-78.

Sreemannarayana, O., A. A. Frohlich, T. G. Vitti, R. R. Marquardt, and D. Abramson. 1988. Studies of the tolerance and disposition of ochratoxin A in young calves. J. Anim. Sci. 66:1703-1711.

Xiao, H., R. R. Marquardt, A. A. Frohlich, G. D. Phillips, and T. G. Vitti. 1991. Effect of a hay and a grain diet on the bioavailability of ochratoxin A in the rumen of sheep. J. Anim. Sci. 69:3715-3723. 